patient who developed cryptogenic organising pneumonia after undergoing lung transplantation for the presence of EBV but found no evidence of EBER 1 or 2 mRNA using in situ hybridisation. A further important point brought out by this case is that, although obliterative bronchiolitis remains the commonest cause of irreversible graft dysfunction following lung transplantation, there are other causes and any patient with atypical clinical, radiological or physiological features should undergo an appropriate biopsy. The value of ensuring lung tissue is prepared for subsequent immuno and molecular pathology as well as routine histology is also borne out by this case.

The case reported by Parry et al describes the course and subsequent clinical effect of pregnancy in a single lung transplant recipient. Although the outcome of pregnancy was successful, the recipient developed obliterative bronchiolitis which stabilised following treatment with total lymphoid irradiation. The clue to the presence of obliterative bronchiolitis prior to the decline in $\mathrm{FEV}_{1}$ lay in the identification of Pseudomonas aeruginosa in the lower respiratory tract at bronchoscopy when the recipient was 15 weeks pregnant. It would be interesting to know whether the flow volume loop suggested airflow obstruction at this time since a reduction in expiratory flow at low lung volumes is a more sensitive physiological index of obliterative bronchiolitis. The potential for pregnancy to have an adverse effect on transplant recipients in terms of an increased risk of rejection remains speculative. The case report reminds us that lung transplantation offers young women the possibility of motherhood but that, as in patients with lung disease such as cystic fibrosis, there is potential for this to be at the expense of her continued health. The delivery of a normal child is, of course, gratifying and in keeping with a number of reports in the transplantation literature. We have experience of three pregnancies in our lung transplant recipients to date, all of which have produced normal healthy children. However, as in this case one mother developed progressive obliterative bronchiolitis after delivery and subsequently died. It is our policy now to advise those transplant recipients who wish to become pregnant to wait two years after transplantation so that their individual risk for developing obliterative bronchiolitis can be estimated and they can be appropriately counselled.

\section{Silicosis presenting as bilateral hilar lymphadenopathy}

\author{
D R Baldwin, L Lambert, C F A Pantin, \\ K Prowse, R B Cole
}

\section{Department of Respiratory Medicine, North Staffordshire Hospital, Stoke-on- Trent ST4 6QG, UK D R Baldwin C F A Pantin K Prowse R B Cole}

Department of Geriatric Medicine, Good Hope Hospital, Sutton Coldfield, Birmingham, UK L Lambert

Correspondence to: Dr D R Baldwin, Department of Respiratory Medicine, City Hospital, Nottingham NG5 1PB, UK Received 9 October 1995 Returned to authors 8 December 1995 Revised version received 21 February 1996 Accepted for publication 27 March 1996

\begin{abstract}
Classical radiographic features of patients presenting with silicosis are diffuse interstitial shadowing with subsequent enlargement of hilar nodes, sometimes with "eggshell" calcification. Five case histories are described of workers who were exposed to silica and presented initially with bilateral hilar lymphadenopathy without radiographic evidence of interstitial lung disease. One case progressed to show features of silicosis.

(Thorax 1996;51:1165-1167)
\end{abstract}

Keywords: silicosis, bilateral hilar lymphadenopathy.

Silicosis is a fibrosing lung disease resulting from the inhalation of free silica. Workers in industries where exposure to silica dust occurs are at special risk of developing silicosis and have regular screening chest radiographs. Classically, the earliest radiographic feature consists of small discrete opacities which gradually increase and may be followed by enlargement of hilar nodes. ${ }^{1}$ In the course of screening employees at industrial plants engaged in producing silicaceous materials for the pottery industry five workers have been encountered in whom the chest radiographic abnormality was that of bilateral hilar lymphadenopathy alone. These workers had heavy exposure to crystalline silica in the form of cristobalite and quartzite. Four had worked in the same sand processing plant and were exposed to cristobalite; the fifth worked a few miles away in the crushing shed of a quarry exposed to quartzite.

\section{Case histories}

\section{CASE 1}

A 28 year old man presented in April 1980 after a routine chest radiograph showed prominent hilar shadowing. Four years earlier the radiograph had been normal. He admitted to having an unproductive cough but was otherwise asymptomatic with no abnormal signs detected on physical examination. He had worked as a dry processor at an industrial sand company for the previous five years. This involved the crushing of red sandstone into a fine powder which was then calcined (heated) to form cristobalite. Before this he had worked as a butcher and briefly as a farm worker. He had never smoked. His blood count and biochemical profile were normal and erythrocyte sedimentation rate (ESR) was $6 \mathrm{~mm} /$ hour. A Mantoux test was positive and Kveim test negative. Pulmonary function tests showed a mild mixed obstructive- 
restrictive defect with a normal transfer factor. Further radiographs taken after October 1981 showed changes suggestive of bilateral upper lobe fibrosis and the latest radiograph taken in January 1996 shows progression to dense but localised upper lobe fibrosis.

CASE 2

This 28 year old man presented in May 1982 when a routine chest radiograph showed bilateral hilar gland enlargement. For the previous seven years he had worked for an industrial sand company mostly as a bagger of silica flour (finely crushed silica sand, principally quartz). ${ }^{2}$ Previous employment had been as a store keeper when aged 15-18 years and a builder's labourer when aged 18-21 years. He was asymptomatic and had not smoked for 10 years. His Mantoux and Kveim biopsy were negative, ESR was $10 \mathrm{~mm} /$ hour, and blood count and biochemical profile were normal. Pulmonary function tests showed a mild restrictive defect. Follow up radiographs to January 1996 showed persistence of hilar lymphadenopathy.

\section{CASE 3}

An asymptomatic 35 year old man presented in 1984 with a radiograph showing bilateral hilar lymphadenopathy and non-homogenous opacities in both upper zones. On review of previous films it was noted that a radiograph taken in 1966 was normal but that bilateral hilar lymphadenopathy had been present since 1975 with the upper zone opacities appearing in 1983. A follow up radiograph in 1987 showed persistent bilateral hilar lymphadenopathy but the lung field opacities had progressed further. From 1967 to 1973 he had worked as a labourer in a pottery. During 1974-81 he had worked as a dry miller of cristobalite, producing silica flour, and during 1981-4 as a wet miller of sand in the same company as cases 1 and 2 . Free silica exposure would have occurred in both the pottery and sand milling industries. A Mantoux test and Kveim biopsy were negative. The ESR was $6 \mathrm{~mm} /$ hour and a sputum smear was negative for tuberculosis.

CASE 4

An asymptomatic 24 year old man was found to have bilateral hilar lymphadenopathy by routine chest radiography in 1980 . Chest radiographs from December 1974 and June 1976 were normal. He had worked for the same company as cases 1,2 , and 3 and had worked for six years as a bagger of silica flour in an area with high dust exposure. A Kveim test and Mantoux test were negative. Pulmonary function tests were normal. Follow up over the following year showed persistence of bilateral hilar lymphadenopathy and no parenchymal changes (fig 1).

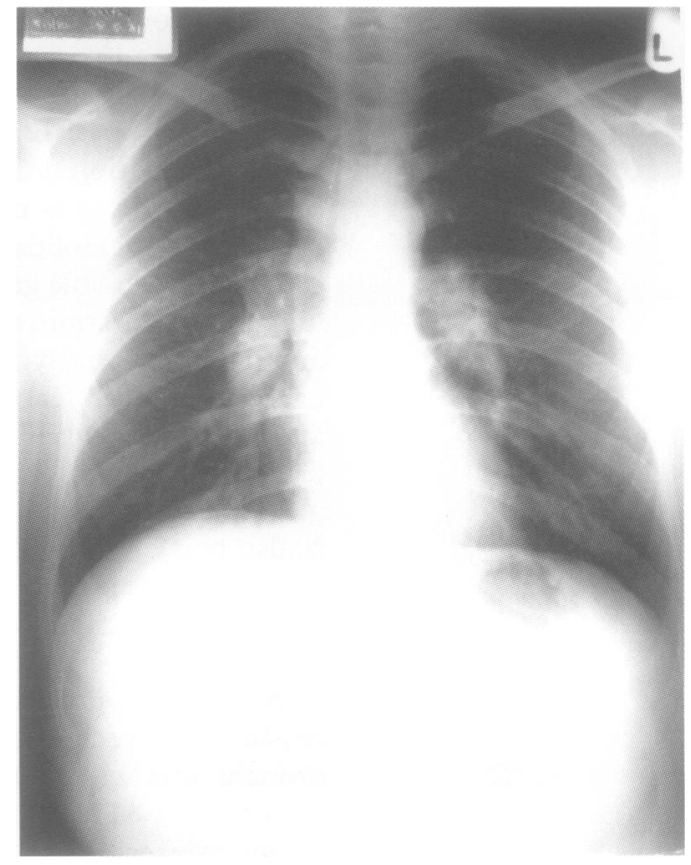

Figure 1 Follow up chest radiograph of case 4 showing persistence of bilateral hilar lymphadenopathy.

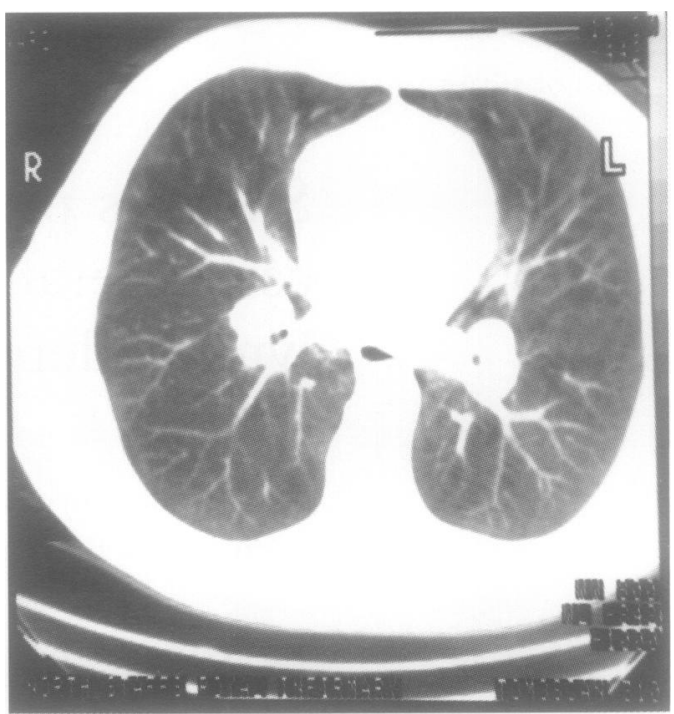

Figure 2 Computed tomographic scan of case 5 confirming bilateral hilar lymphadenopathy with no abnormality of the lung parenchyma.

CASE 5

This man presented at the age of 49 years in 1987 when bilateral hilar lymphadenopathy was shown on chest radiography. $\mathrm{He}$ was asymptomatic and had spent the preceding 23 years as a quarry worker mainly in the crushing shed exposed to quartzite. Standard resolution thoracic computed tomography in 1988 confirmed bilateral hilar adenopathy with no abnormality of the lung parenchyma (fig 2). Full blood count, biochemical profile, bronchoscopy, and pulmonary function tests were all normal. A Kveim test was negative but Mantoux test was not performed. Follow up to 1993 shows bilateral hilar lymphadenopathy only. 


\section{Discussion}

The major differential diagnoses to be considered in these five cases are sarcoidosis and berylliosis. Coal worker's pneumoconiosis is excluded by the absence of occupational exposure. Berylliosis is extremely rare in the UK and requires exposure to beryllium which is used in the nuclear industry and in the manufacture of $x$ ray tubes.

Sarcoidosis is therefore the major differential diagnosis of the hilar adenopathy seen in the above cases. Although all had a negative Kveim biopsy, this test is positive in only $70 \%$ of cases of sarcoidosis and it is therefore conceivable that these were all cases of sarcoidosis and the industrial exposure was coincidental. However, there were no other features of systemic sarcoidosis such as erythema nodosum, uveitis, parotitis, bony lesions, or fever. Lung or mediastinal biopsies were not performed as this was felt not to be clinically justifiable in fit asymptomatic subjects. There were no skin lesions from which biopsy specimens could be taken and the test for angiotensin converting enzyme was not available at the time these cases presented; in any case it is not a diagnostic test. It is unlikely that these cases represent the natural incidence of sarcoidosis in the general population because relatively few were screened. At the sand processing plant where four of these cases occurred there were 150 employees of whom at most 25 suffered heavy exposure. Assuming a 10 year screening period this represents an annual incidence of 0.4 per 25 or 1600 per 100000 . The annual incidence of Kveim biopsy negative sarcoidosis is estimated at 0.9 per $100000^{34}$ and for those presenting with bilateral hilar lymphadenopathy it is even lower.

All five subjects had heavy exposure to silica dust over a period of years and it is likely that the bilateral hilar lymphadenopathy was a feature of silica exposure. Hilar lymphadenopathy in silicosis is well known and as such is not an unusual observation. Animal models of dust inhalation have shown that silica is cleared via the lymphatics to the hilar lymph nodes and that silica accumulates there. ${ }^{5}$ However, previous descriptions ${ }^{1}$ suggest that bilateral hilar lymphadenopathy is accompanied by marked interstitial shadowing on the chest radiograph and often by eggshell calcification of the lymph nodes. Animal models of silicosis have demonstrated early transport of silica to regional lymph nodes, but have not shown regional lymphadenopathy without lung parenchymal changes.

The likelihood of silicosis developing depends on the level of exposure and the type of silica encountered. The principal crystalline (fibrogenic) forms of silica are quartz, tridymite, and cristobalite. Exposure to crystalline silica occurs in the quarrying, sandblasting, and mining of silicaceous rocks, in the production of fillers, ceramics and refractory (or fireclay) brick, in foundry work, and in the manufacturing of cristobalite sand from diatomaceous earth. Diatomaceous earth consists mainly of the fossilised skeletons of a unicellular aquatic plant related to the algae and biologically dependent on silicon. In this form it is harmless to man, but processing usually involves heating to temperatures of $816-1700^{\circ} \mathrm{C}$ (calcination). Depending on the processing method, cristobalite or tridymite is produced. The fibrogenic potential of crystalline silica increases from quartz to cristobalite to tridymite. In the first four cases exposure was to cristobalite and the time to presentation was 6-7 years; the fifth case worked in a quarry, was exposed to quartzite, and presented after 23 years exposure. None of the men had worn respirators and all had worked in sheds where there was heavy dust exposure. This type of exposure is now uncommon as working practices in this industry have changed.

These cases suggest that, in the context of occupational exposure to silica, bilateral hilar lymphadenopathy may be the sole initial radiographic abnormality.

We acknowledge the contribution of Dr J S Washington of the National Coal Board Radiological Centre who first drew our attention to the type of radiological changes we have recorded in this paper. We wish to thank Hepworth Minerals and Chem ical Ltd, Sandbach, Cheshire for providing us with details of the processing and composition of the described forms of silica.

1 Parkes WR. Occupational lung disorders. 2nd edn. London: Butterworths, 1982

2 Silica flour. Hepworth Minerals and Chemical Safety Data Sheet no. 260. Hepworth Mineral and Chemicals Ltd, Brookside Hall, Sandbach, Cheshire.

3 Anderson R, Brett GZ, James DG, Siltzback LE. The prevalence of intrathoracic sarcoidosis. Med Thorac 1963;20. 152

4 British Thoracic and Tuberculosis Association. Geographic variations in the incidence of sarcoidosis in Great Britain: variations in the incidence of sarcoidosis in Great Britain:

5 Klosterköller W, Bünemann G. Animal experiments in the elimination of inhaled dusts. In: Davies CN, ed. Inhaled particles and vapours. Vol 1. Oxford: Pergamon, 1961:327-
41 . 